\title{
A PARTICIPATIVE APPROACH TO FORWARD PLANNING AND SYSTEM CHANGE
}

\author{
John Hawgood \\ Frank Land \\ Enid Mumford
}

Automation Benefit Appraisal Consultants Ltd.

Durham DH1 4DY, England

(Most of this paper is based on an article commissioned from us by the UNESCO journal "Impact of science on society" for its jssue (Vo1.28, No.3, July-September 1978), which is devoted to the theme "Computers and social options". Permission of UNESCO to use this material here is gratefully acknowledged.)

\section{ABSTRACT}

Forward planning and system design can be improved through the participation of the people who will eventually use the system, if they can be provided with the necessary skills. The authors have developed and tested a framework for participative forward planning and aystem design which includes a set of analytic and design procedures:

1 Variance analysis, for identifying operational deficiencies

2 Job satisfaction analysis, for measuring the lack of fit between employees' actual and preferred work situations

3 Future analysis, to identify significant opportunities and development goals

4 The BASYC approach to multi-attribute utility analysis, to compare the desirability of alternative courses of action (possibly using "fuzzy logic")

5 Socio-technical systems design, to bring human and technical factors to bear simultaneously on system improvements.

John Hawgood, University of Durham, Durham DH1 3LE, Eng1and Frank Land, London School of Economics, London WC2A 2AE, England Enid Mumford, Manchester Business School, Manchester M15 6PB, England 


\section{INTRODUCTION}

It is gradually being recognised that systems design, like management in general, is primarily about people. Many past failures of computer-based information systems can be directly attributed to two complementary causes:

1 A lack of knowledge of human needs and motivation on the part of technically oriented systems analysts and designers

2 A lack of technical confidence on the part of general and departmental managers which makes them reluctant to intervene in design decisions

The long term answer must lie in the education of specialists and users, but two present day trends provide a means for improving the situation. These are, first, the movement towards employee participation in forward planning and work design and, second, the trend away from conventional money based cost-benefit analysis and towards multiattribute utility analysis which takes account of all the different types of advantages and disadvantages associated with any proposed change. The authors have developed a method which combines these two elements in a formal yet flexible participative framework in such a way that a number of related techniques can be applied as and when needed. Our approach is based on four important value judgements:

1 That the financial, human and technical factors in system design can and should be treated compatibly

2 That everyone affected by a system change can and should be considered in planning it

3 That employees at all levels can and should design their own systems

4 That the overall approach to systems design and development should be based on the principle of reducing uncertainty

In our view the process of forward planning, including systems design, implementation and evaluation, should be carried out by two types of team. The first team is a steering group which sets the basic organisational objectives and constraints under which the new system is to be developed. It will general1y include the managers of affected departments, official representatives of trade unions and other major interests affected by the new system. The second team is responsible for the detailed systems design and consists mainly of representatives of the department where the new computer system is to be introduced. This team will define the scope of the $10 c a 1$ problem, scan the environment for new opportunities or changing constraints, analyse deficiencies in the current system, define development goals in consultation with other groups likely to be affected and provide decision makers with assessments of the likely impacts of alternative strategies on these goals. Finally it will design and test the selected system and the work organisation and task structures associated with it. 
Such a team may include members from the traditional EDP department, but their function will be to transfer the required skills to other members rather than to carry out the design themselves.

\section{BACKGROUND}

Economic analysis of information systems

The introduction of computers into an organisation's information system generally requires substantial resources. In order to justify the use of such resources, the organisation has to set-off the development costs against the net benefits the changes bring to the organisation. Benefits may accrue to the organisation directly through a reduction in costs or an increase in production, or indirectly in that the changes in the information system enable the users of the system to perform their functions more effectively. Further, some of the benefits of the changed system have an effect on the organisation through the changed behaviour of the customers or the improved image of the organisation in the community. Thus the concept of a net benefit to the organisation as a measurement of the benefits accruing to the organisation over the life-time of the project, less the cost of operating the changed system over that time, contains a number of practical and theoretical difficulties (1).

In practice there have been a number of different approaches to solving the problem of evaluating the worthwhileness of systems changes. At one extreme (2), organisations will only accept systems change projects if it is possible to demonstrate that the change will result in directly measurable savings.

At the other extreme $(3,4,5)$, cost benefit analysis techniques are suggested which attempt to provide an economic value measured in money terms for all costs and benefits, whether these be measurable through the normal accounting system or not.

A new approach has recently begun to take favour. This recognises that an organisation has many goals and that any goal may be regarded as having a different value by different groups within the organisation. Some goals may appear to be conflicting; for example, it may be desirable to have both an efficient system (operating at minimum costs) and a flexible system. It is difficult for a system to be both optimally efficient and very flexible.

Multi-objective, multi-criteria decision methods are being developed all over the world $(6,7,8)$ and have found a number of applications in the evaluation of computerbased information systems $(9,10,11)$.

The approach to evaluation chosen here is based on this approach, which has been shown $(12,13)$ to overcome some of the problems associated with other techniques of analysing the expected value to the organisation of making a change in the information system. 
The planning and management of change

This paper has two objectives related to the management of change. First, it seeks to legitimate a value position in which the future users of computer systems at all organisational levels play a major part in their design. The argument here is that people have a moral right to influence the organisation of their own work situations and that if this right is conceded then there are likely to be both job satisfaction and efficiency gains: job satisfaction gains because the group are better able to diagnose their own job satisfaction needs than any outside group of specialists; efficiency gains because the people who are in the change situation are likely to have an excellent knowledge of day-to-day work problems and can make useful contributions to the solution of these. Also, it is hypothesised that they will be committed to operating efficiently a work system which they have designed $(14,15)$.

The second objective of the paper is to persuade groups concerned with the design of computer systems to set specific job satisfaction objectives in addition to the usual technical and operational objectives. Here we argue that unless job satisfaction objectives are made explicit, and the computer system and associated organisation of work designed to achieve these, then the human consequences of a new computer system will be unpredictable because they have not been consciously planned for. The result can be that the new system will have undesirable human consequences such as a routinisation or deskilling of work, or other features that are not welcomed by the user. Employees in the user department may then respond in a negative way, refusing to operate the system or ensuring that it runs at low efficiency, and, in addition, absenteeism and labour turnover may increase.

Our belief is that greater user involvement together with clear job satisfaction objectives will assist the successful planning, design and implementation of computer systems. Ozbekhan, discussing theories of planning, suggests that the raison d'etre of any planning is to change the environment in a manner that is smooth, timely and orderly so that a dynamic evolution that is in line with our ideas of organisational progress can be achieved (16). He also points out that because the objective of planning is change it is likely to be a threat to people, unless the different groups associated with the change believe that they are participants in the change process. We would support this view.

Figure I sets out the authors' perceptions of the risks associated with the traditional approach to the design of computer systems in which planning and design responsibility rests with a group of EDP specialists.

If a group believes that it is threatened by another group it is likely to draw together to show a collective identity and to introduce group norms directed at emphasising group unity and solidarity. This response enables it to reduce uncertainty by introducing behaviour patterns which are seen as helpful in protecting the interests of the 


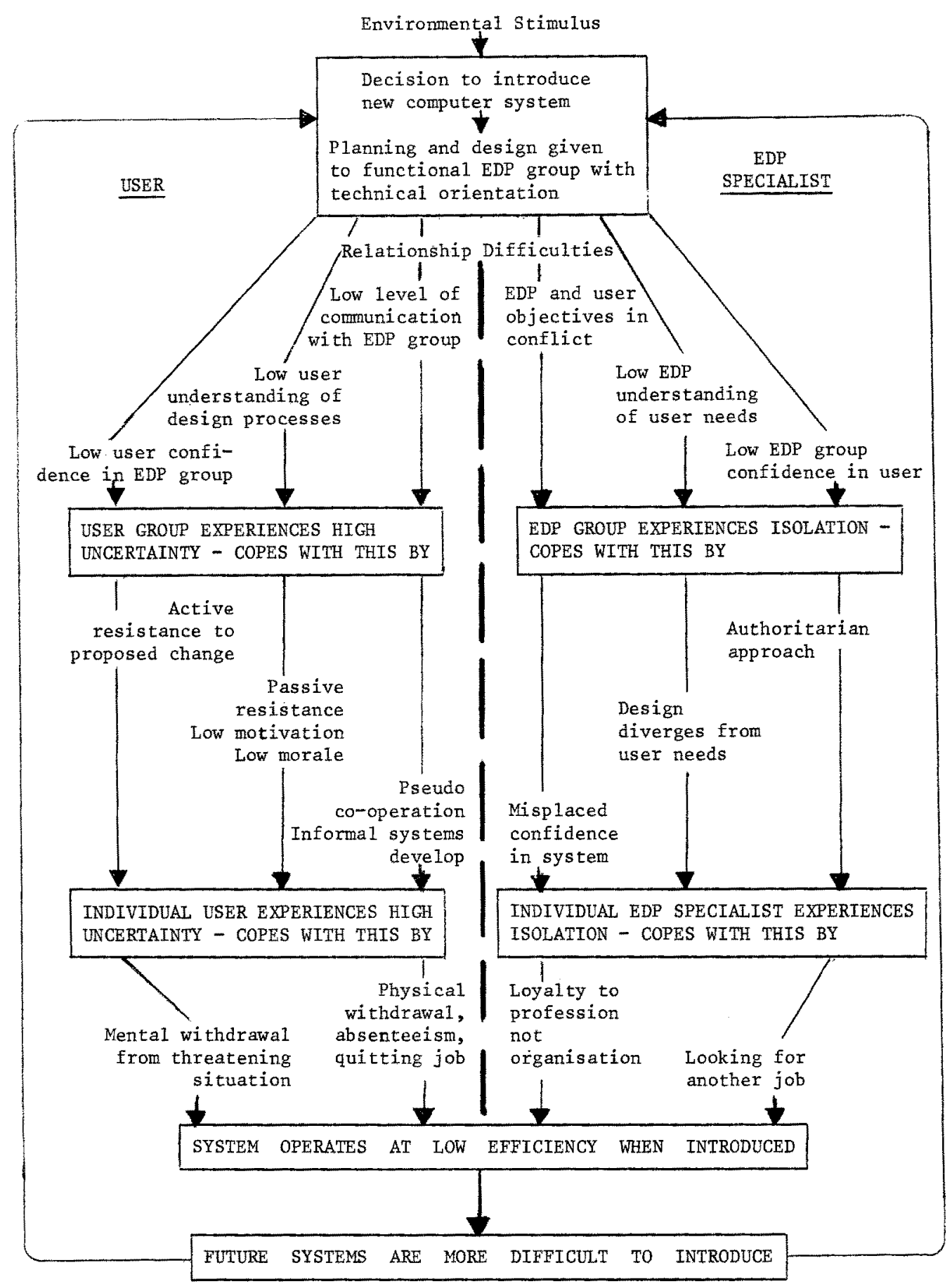


group. If the response of the threatening group is one of increased pressure on the threatened group to conform, conflict will increase. It has been suggested that negative actions feed upon each other (17). If one group acts with hostility towards another, then this will provoke a counter action. Also if two groups have an interdependent relationship - that is, they are unable to work in isolation and depend upon each other's services for the successful completion of a task - then hostility is likely to be increased, for they are forced into a constant and irritating association. All of these statements seem applicable to the traditional relationship between EDP specialists and user groups.

Planning and design approaches that tend to generate rather than reduce conflict place the organisation in a risk situation. It may incur financial risks through introducing expensive computer systems which operate at low efficiency, or reduce job satisfaction and increase labour turnover. Many firms underestimate the cost of labour turnover, which can be very high (18). The firm may also incur organisational risks, for a poorly functioning department may spread dissatisfaction and inefficiency through departments which interact with it. In addition there will be human relations risks. A new cormuter system that is introduced against the wishes of a user department has the potential to produce serious industrial relations problems (19).

We are therefore suggesting that the technical and user groups associated with the introduction of a new computer system are unlikely to have a complete identity of interest, and may have major conflicts of interest. The EDP specialists will be keen to optimise the use of a technology which they know and understand and this can lead them to design systems which have a high technical competence but are poor at catering for human needs, such as a desire for job satisfaction. The user group which has no active role in the design process is unlikely to be able to challenge the technical knowledge of the specialists and this can force it into a dependency relationship, and the subsequent acceptance of a computer system which does not adequately meet its needs. This produces low comitment to the system together with increased resistance to any future change.

A participative design approach such as we recommend in this paper enables the user group to identify $i$ ts own needs and interests, to turn these into design objectives and to see that these receive equal weight with technical objectives. This is the basis of the socio-technical design method described below, which has as its objective the design of work systems so as to secure joint optimisation of technical and human needs (20). Figure 2 sets out our view of the advantages of a participative approach as a facilitator of change that in ozbekhan's terms is 'smooth, timely and orderly'.

Such an approach enables conflicts to be resolved or at least recognised, so that evasive action can be taken, or a consensus arrived at, on the objectives that should be attained through the new computer system. Because planning and design responsi- 
Figure 2

SYSTEMS PLANNING AND DESIGN

The advantages of the approach described

in this paper

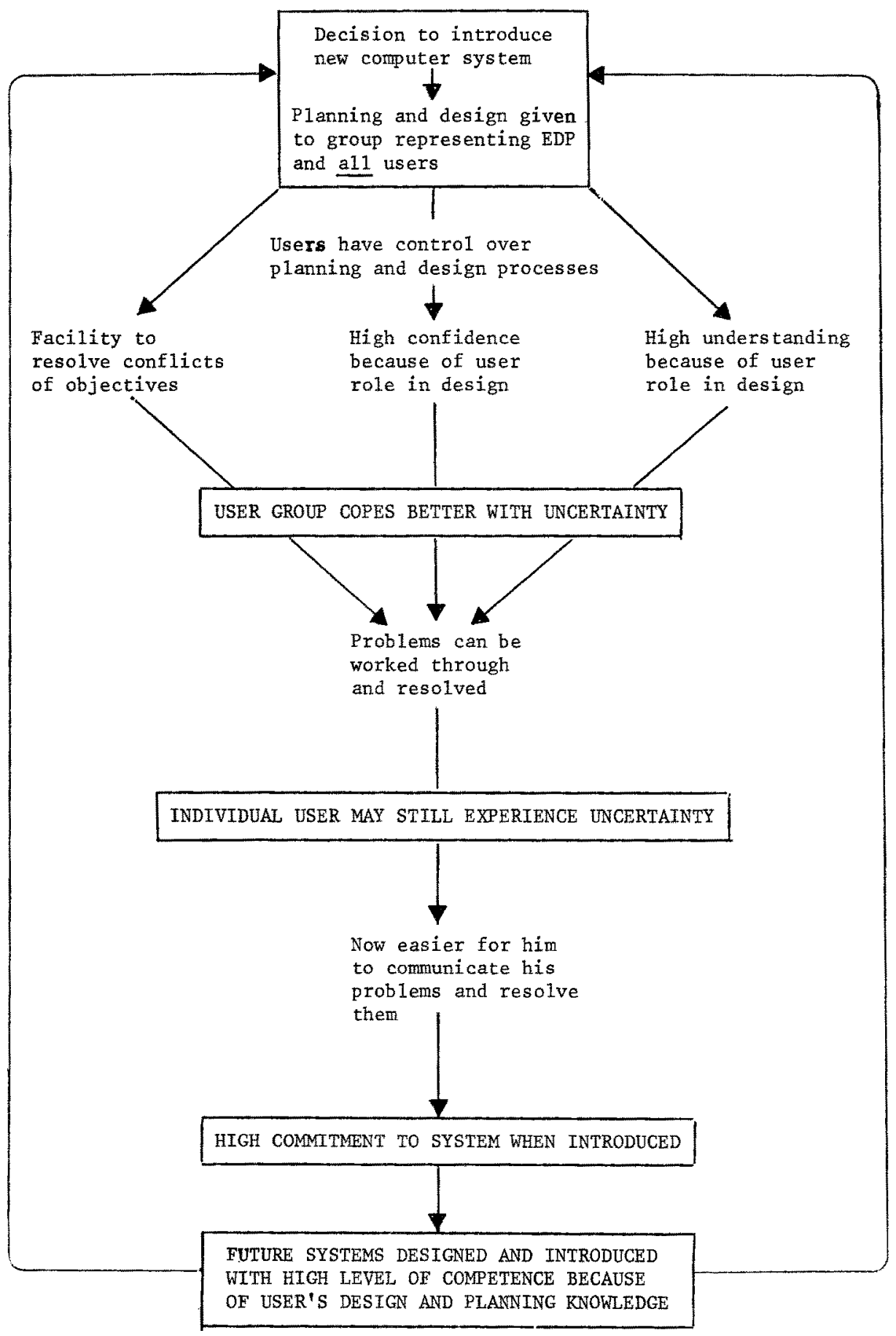


bilities are shared between technical experts and users, competences are shared and each group can learn from the other. Perhaps most important of all is the fact that user values on participation and on the organisation of work can be catered for. Today many groups of employees are seeking greater involvement in decisions which affect them and a more interesting and challenging work environment. We believe that the use of our method will assist the achievement of both of these objectives.

\section{THE PARTICIPATIVE PROCESS}

Systems design can occur at three different organisational levels: the top where it is concerned with strategic planning, the middle where it covers system definition for a number of divisions, functions or departments, and the bottom where it relates to the detailed design of an organisational subsystem serving a single department or function. The participative approach can be used at al1 of these levels although it may take a different form depending on whether it is concerned with higher or lower level systems. These different forms have been natned by the authors consultative participation, representative participation and consensus participation (see Table 1).

The consultative approach is seen as most appropriate for securing agreement on strategic planning objectives. Here the major planning decisions are taken by senior management, probably at Board level, whose hierarchical position enables them to take a broad view of the enterprise's future needs. However they will only take these decisions after extensive consultation with interested groups lower down the organisational hierarchy and a consultative structure must exist or be created so that this sounding out of opinion can be thorough and accurate.

Representative participation is seen as appropriate at the system definition stage when powerful interest groups at middle management level will wish to express an opinion on where system boundaries are to be drawn and on the broad form any future system should take. Representative design teams will include selected or elected representatives of all grades of staff and all trade union interests in the departments which a new system will affect.

Consensus participation attempts to enable all the staff in a department to play a part in the design of a new work system. They are involved when efficiency and job satisfaction needs are being diagnosed through feedback and discussion in sma11 groups. As the design team formulates alternative design strategies these will be discussed at staff meetings and the choice of work organisation and task structure to be associated with the technical part of the system will be greatly influenced by the views of the staff. Experience has shown that a consensus on a system solution does not always emerge easily and conflicts which result from different interests within a department may have to be resolved first. 


\section{PROCEDURES TO ASSIST PARTICIPATION}

\section{Variance analysis}

An important prerequisite to designing an improved system of work is a detailed knowledge of those weak parts of the existing system which produce operational problems. The method used to obtain this is known as variance analysis and was developed by Professor Louis Davis of the University of California, Los Angeles (21). A design group which uses this approach will examine in detail all the different operations which a department or section undertakes and note areas where variances are prone to occur. By variance is meant a tendency for the work system to deviate from a desired standard or specification. This tendency arises as a result of some problem associated with the work process itself in its normal operation. Variance analysis is not concerned with temporary problems such as machine breakdown or with human errors which are a result of inadequate training. It concentrates on system weaknesses associated with the organisation of work operations. An important objective of the method is to identify clearly those key variances that significantly affect the ability of a work system to pursue $i$ ts major objectives. These variances are often found at the boundaries of a system, for example, where the work of one department interacts with that of another and there are problems of co-ordination.

Once variances have been identified they must be examined in detail in order to determine the following:

\footnotetext{
1 where the variance originates

2 where it is observed

3 where it is controlled (corrected)

4 who has responsibility for this control

5 what he does to control it

6 what information he requires to restore control and where he gets it from

7 possible alternative control mechanisms (of which a computer may be one)
}

Variances are frequently controlled not where they originate, but later by supervision. A good design principle is to ensure that corrections are made as close to the source of the variance as possible.

Many variances interact with others, thus causing a set of problems that affect the efficiency of the work process from the input to the output stage. A variance matrix is a useful method for showing this interlinking. An example of a simple variance matrix for a department dealing with customer orders is set out as Figure 3 . It shows how variance 1, orders which incorrectly identify goods required, and variance 3, too many orders for staff to handle, have the greatest impact on the total work system. Particular care must therefore be taken when redesigning the technical and human parts of the work system to get these two variances under better control. The computer can be of assistance here. 


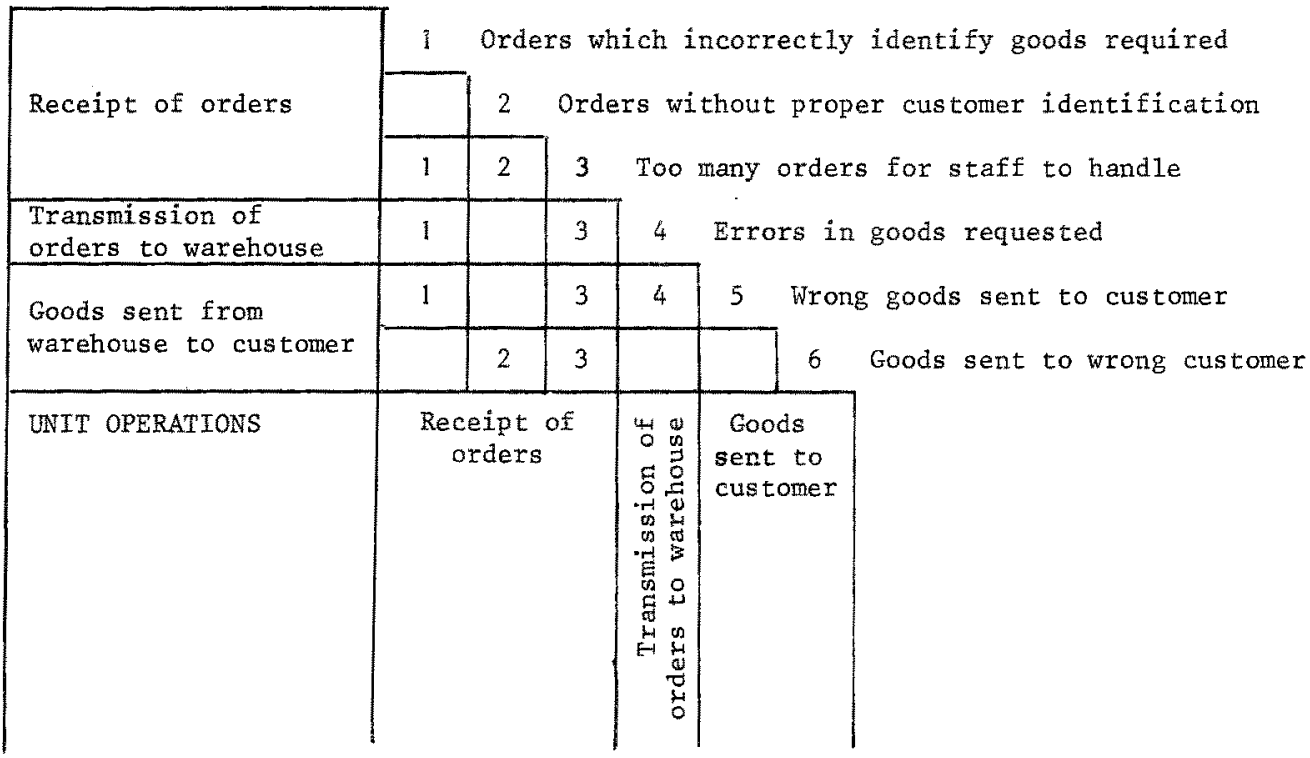

This example shows some of the variances associated with a line department with one functional activity. The same approach can be used at different levels in the organisation, for example, identifying the variances of a research and development department or a planning activity.

Alternatively, a single manager can be used as the unit of analysis and his personal variances identified. This last approach would prove useful when designing information systems.

A major part of the socio-technical design task is to eliminate system variances or enable these to be more effectively controlled. If a computer system is being introduced then its ability to assist the elimination or control of variances is one measure of its efficiency.

Job satisfaction analysis

Job satisfaction is defined by Mumford as the FIT between what an individual or group is seeking from the work situation and what they are receiving from it, in other words the FIT between job needs and positive expectations and the requirements of the job (22). Job satisfaction is seen as being achieved when three kinds of needs are met in the work situation. These are personality needs, competence and efficiency needs, and needs associated with personal values. It can be argued that an improvement in job satisfaction should always be made a design objective and a design group concerned with job satisfaction should be able to answer the following questions: 
Needs associated with personality

1 Knowledge needs: To what extent does the existing organisation of work meet the needs of the group of employees which the design group represents for work that fully uses their knowledge and skills, and to what extent does it provide them with the opportunity to develop their knowledge and skilis further?

2 Psychological needs: To what extent does the existing organisation of work meet the needs of employees for recognition, responsibility, status, advancement, esteem and security? Does it also give them a sense of achievement?(23)

Needs associated with competence and efficiency in the work role and the successful performance of work activities

3 Support/control needs: To what extent does the work situation provide employees with the kind of support services which enable them to carry out their job efficiently? These support services include the information and materials necessary to work at a high level of competence, supervisory help, and encouragement and good working conditions. We are here making an assumption that an efficient and supportive work environment increases job satisfaction. To what extent also does the way work is controlled through checks and audits fit with employee ideas and wishes on how their work should be controlled? The level and structure of wages and salaries will be an important part of the control system.

4 Task needs: To what extent does the way in which work is organised and jobs designed meet employee needs for the following?

a) the opportunity to use a variety of different skills and different levels of skill.

b) the opportunity to achieve targets, particularly quality targets, and to obtain feedback on how well these targets have been achieved.

c) Autonomy. The opportunity to take decisions, exercise choice and exert a degree of control over what is done and how it is done.

d) Task identity. The opportunity to undertake work which is viewed as important, which is organised in such a way that the work of one group is clearly separated from the work of other groups, and which has a reasonably long task cycle so that an employee can look back with pride on the way in which he has solved a particular work problem or carried out a challenging set of tasks (24).

Needs associated with employee values

5 Ethical needs: To what extent does departmental management, and senior management also, treat employees in the way they think they should be treated? This 
applies particularly to issues such as communication, consultation and opportunities for participation in decisions which affect employee interests.

This job satisfaction information can usefully be collected by questionnaire provided that three important criteria are met:

(a) The information is collected in such a way that employees are convinced of its confidentiality.

(b) Aggregate data derived from analysis of the questionnaires is given to everyone who completed a questionnaire.

(c) Questionnaire data is discussed with all employees who complete a questionnaire in small groups. This will check its accuracy, provide an understanding of the reasons for high and low satisfaction and get employees involved in improving the design of their own work organisation.

Variance analysis and job satisfaction analysis will provide essential diagnostic data for gaining an understanding of existing efficiency and job satisfaction problems. In addition there is a need to identify future needs, so a 'future analysis' is also required.

\section{Future analysis}

The time taken to design, construct and implement a computer-based information system will depend on the scale of the planned change and the resources available to make the change. Even quite small systems changes take substantial time and resources, whilst the implementation of major systems may require a period of several years. Time cycles of three to five years are not uncommon for the period between the start of an information systems project and its implementation.

To recover the cost of development, to cover the operating costs and to provide an adequate return on the capital employed, the system might be expected to be operated for a number of years before it is replaced by a new system.

Suppose it takes three years from project start to project implementation and a further five years of systems operation before the advent of a new technology makes it advantageous to design a new system, which itself takes two years to design and implement. Then the system which is being planned at A in Figure 4 will have to meet the requirements of the organisation not only three years later when it is implemented, but also through its lifetime of seven years. In other words, those who design the system must be capable of foreseeing the needs of the organisation ten years later. 


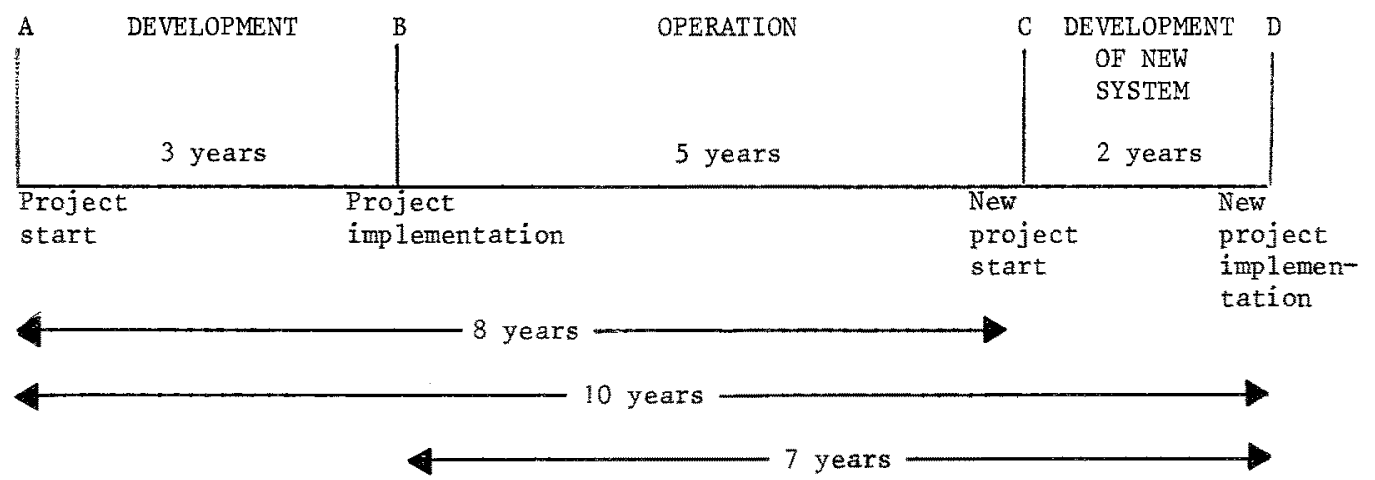

Many types of changes may have an impact on the information system; for example, the development of new technologies, revisions in the organisation's structure, alterations in the organisation's management style, changes in the attitude of employees to work, new laws, changes in the economic climate, or alteration in the organisation's scope or function.

In order to design a system which meets the future as well as the present requirements of an organisation, the systems designers have to:

1 predict the kind of changes which could occur over the expected life time of the system

2 predict the extent to which the kinds of changes outlined above will have an impact on the jobs the systems have been designed to carry out. In other words, how sensitive is the system to changes?

Because it is inherently impossible to build a completely flexible, completely portable system capable of coping with any change, we have to define in some way the extent of change it is possible to accormodate.

The further the designers look into the future the more they are faced with uncertainty regarding the changes that may occur and the potential impact on the system they are designing. At some point in the future the uncertainty is so great that the system designers cannot conceive of any design which can cope with a possible range of circumstances. That point of time is called the forecasting horizon.

In practice the forecasting horizon will vary from organisation to organisation and will vary in different epochs. At times of high technological change, such as now, with the coming availability of new micro-computer technology, the forecasting horizon is closer to the present than at any ocher time. A similar effect is noted at times of economic instability. Some organisations have a very stable environment and hence can forecast with reasonable certainty over quite long periods, others live in a much 
more dynamic or uncertain world and forecast for a short period ahead.

No systems designers can plan to build systems on an assumption of a system life which could go beyond the forecasting horizon. The planning horizon for a new system must lie within the forecasting horizon. The expected life time of the system then is related to the planning horizon of the system.

The traditional method of designing computer-based systems has not in general dealt with the future uncertainty adequately, and the actual as opposed to the expected life time of the systems have been disappointing. The problems stem from the division of function between user and specialist EDP departments. The user department manager:

a) is not aware of the inherent lack of flexibility of the computer-based system,

b) does not realise the sensitivity of the system to different kinds of changes,

c) regards many aspects of future policy as being outside the scope of discussion and, in many cases, regards questions of future policy as confidential.

Hence, he makes no special effort to predict the kind of changes which might occur. A specialist designer, in concentrating his efforts on finding a technical answer to meet the immediate problem, is unaware of the dynamic nature of his environment and the extent of uncertainty about the future. The level of communication between user and specialist regarding the future tends to be low and unstructured.

The solution lies with a structured approach to future analysis. The two groups involved in the design process - the steering group and the design team - join together in the first instance to attempt to define the forecasting and planning horizon for the system. At this stage the scope of the new system has already been defined and the groups have some rough idea of the expected life of the system. Changes can affect the system by a change in the system's logic, or by a change in activity levels.

The structured process involves, first, drawing up a list of factors relevant to the system which are subject to change, and second, assessing the likelihood of the factors changing significantly over the expected life time of the system.

This completes the diagnostic stage of our approach. The next step is to set objectives and evaluate alternative strategies for meeting the needs identified in the variance, job satisfaction and future analyses.

\section{Benefit assessment}

Our approach to multi-attribute utility analysis, which we call BASYC (Benefit Assess- 
ment for System Change), expresses the benefits of alternative policies to different groups of people in terms of relative progress towards the goals important to them. The BASYC approach is intertwined with the other procedures described in this paper, but its key concepts can be displayed simply:

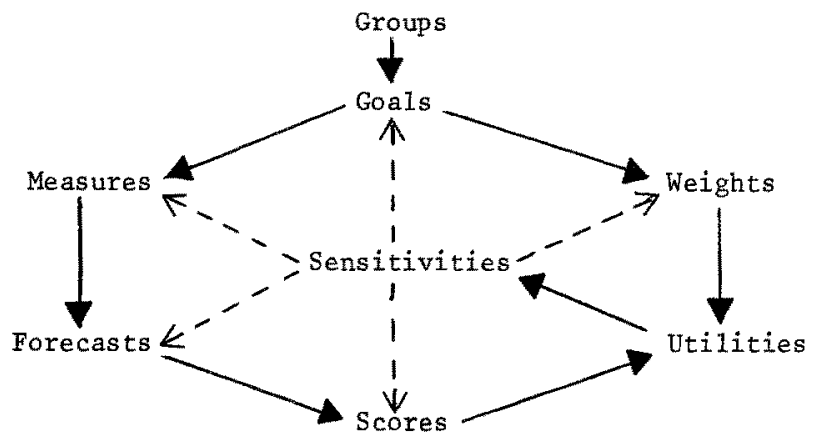

The sequence is shown without an exit to emphasize that a decision "emerges" after a number of cycles of discussion held by members of the design team with their constituents, with other interest groups and with their steering committee. The discussions are guided and disciplined by the formal structure of utility calculation, but as the diagram shows, the sensitivities are central to the pattern.

The word "sensitivity" is used in two senses here; both in its mathematical sense in which it means the extent to which a value would change if one or more of the input variables changed - and in its conversational sense - drawing attention to the effect of proposed policies on the feelings of the people involved.

The detailed steps the design team will carry out in the benefit assessment sequence are as follows, when using numerical measures at the starred points:

Identify interest groups which are not already represented in the team (customers, owners, managers, taxpayers, ...), paying particular attention to any subgroups that might suffer from proposed changes.

Shortlist the measurable goals, relevant to the situation being studied, which are most important to all the interest groups (including here both groups which have direct representation on the design team and those which have indirect representation). The techniques of variance analysis, job satisfaction analysis and future analysis will provide a great deal of the information required to do this.

Assign a weight* to each goal for each group to represent its importance to that group in relation to the other goals; this should be done in consultation with members of the group. Job satisfaction must always be included as a goal for internal groups. (For calculation of utilities these weights are converted to 
percentages so that the total weight of all goals for any one goal is 100.)

Estimate current measures* (often several are required for each goal) and set target measures for the planning horizon date; again all three of the analytical techniques will provide information for these measures. Guesswork (by people who know the current system) is good enough for the first cycle - later, sensitivity analysis will determine where better values are needed.

Define alternative systems strategies for comparison with the current system (as it will be after any changes already decided); this is the beginning of the socio-technical design phase, and at the preliminary stage a few "wild" ideas are quite advantageous as they often suggest practical strategies not generated otherwise.

Forecast* the effects of the alternative strategies on the measures at the planning horizon, doing this both optimistically and pessimistically as outlined in the future analysis section above. Again the sensitivity of recomendations to assumptions will determine how much effort to put into refining forecasts.

Score* each strategy for its success in meeting each goal as seen by each group using a scale running from -10 (change very much worse than existing system) through $O$ (same as existing) to +10 (change very much better than existing system). Note that the comparison is between the changed system at the planning horizon and the existing system also at the planning horizon. Different optimistic and pessimistic scores corresponding to different trends are often needed. often the scores will be the same for all or most of the groups, but this needs checking as groups' ideas on what constitutes "success" may differ. This scoring operation needs human judgement; it is not mechanical.

Calculate utilities* by multiplying each percentage weight (for each goal for each group) by the corresponding score (for each goal for each group for each strategy) and ading over all shortlisted goals. This is a purely mechanical operation, conveniently done by computer. The result will be coptimistic and pessimistic) utilities for each strategy as seen by each group. The numbers obtained are not important in themselves - what we are seeking is the ranking order of the alternative systems as seen by each group and, more important, the sensitivity of the ranking order to changes in goals, weights, measures, scores or assumptions.

Consider the sensitivities carefully to decide what further investigations are required; often it can be seen that some strategies can be discarded, and occasionally all agree that the right decision has emerged - but more often a new or compromise strategy will require examination in a further cycle before an acceptable solution is found. The actual decision when "enough is enough" must always 
remain with management - or with the steering committee if this power has been delegated to it.

It must be emphasized that a number of the stages of benefit assessment are likely to be negotiating processes as the representatives of different interests on the design team press for priority to be given to those goals and strategies most likely to further the needs and expectations of their constituents. One advantage of the method is that these issues are brought out into the open.

When a decision to proceed does emerge, the team will usually go on to the full sociotechnical design process, described below. This may itself be iterative - with initial cycles corresponding to design of prototype systems or part-systems, followed by BASYC cycles to check on likely benefits as compared to those estimated in the assessment stage.

The BASYC approach has been applied in two major projects: comparison of alternative computerisation schemes in savings banks (25), and benefit assessment in public libraries (26), the latter being an application not involving computer systems design at a11. Two short-cut methods were developed for use in the library project: MINIBASYC for initial training and SEMIBASYC for simple real problems (27).

\section{Fuzzy approach to benefit assessment}

One of us (JH) is now engaged, with Janet Efstathiou and Vladislav Rajkovic, in applying the concepts of "linguistic variables" and "fuzzy algorithms" (28) at the starred points in the BASYC approach. The use of numerical weights, measures, scores and utilities is abandoned - partly because of the spurious precision which numbers convey to the statistically unsophisticated participant, but more because some important theoretical obstacles concerning orthogonality of goals and aggregation of utilities are thereby surmounted - or, rather, the obstacles simply disappear.

In this new variation, weights may be expressed as "very important", "rather important", "not important", ....., measures in terms appropriate to individual goals (e.g. "comfortable", "prompt", "cheap", "accurate"), and comparative benefits as "much more acceptable", ....., "much less acceptable".

The final comparative rankings will be derived direct from the linguistic measures without use of "partial utilities", by fuzzy algorithms chosen by the design team (within the rules of fuzzy logic) to represent the decision processes of the different interest groups, real members of these interest groups being consulted about this.

\section{Socio-technical systems design}

A participative approach to work design means that the employees of a department or their representatives construct a new form of work organisation which is based on a 
diagnosis by them of their own needs. There are a number of philosophical approaches to work design which such design groups may want to consider. The two most frequently used are job enrichment and the socio-technical approach. Job enrichment focusses on the job of the individual worker and tries to build up this job in such a way that it increases in interest, responsibility and challenge. The job may be extended by adding to it preliminary activities such as setting it up and acquiring the necessary materials, or completion activities such as final quality inspection and the rectification of errors, tasks which previously have been carried out by other individuals. The aim of job enrichment is to improve the relationship between the individual and his work.

The socio-technical method was originally developed by the Tavistock Institute in Great Britain and this takes a very different approach. The concept of a sociotechnical system is derived from the premise that any production system requires both a technology, a process of transforming raw materials into output, and a social structure linking the human operators both with the technology and with each other. A socio-technical system is any unit in the organisation composed of a technological and a social sub-system having a common task or goal to accomplish (29). If we are concerned with clerical systems based on the use of a computer, the technical system will consist of the tools, techniques and procedures used for processing the raw material of information. The social structure is the network of roles, relationships and tasks which interact with the technical system. The purpose of the socio-technical systems approach is to produce technical and social structures which have a high capacity to achieve technical and social goals, and which reinforce each other in the achievement of these goals.

Socio-technical analysis incorporates a logical analysis of the technical components of the work system (machines, procedures, information) and the grouping of these into 'unit operations' (21). Unit operations are logically integrated sets of tasks, one set being separated from the next by a change of state in the input or product. For example, in a Purchase Department the tasks of preparing accounts data for a computer, putting the data into the computer and correcting errors is a logically different set of activities from matching accounts with goods received notes and investigating discrepancies. Work design which uses a socio-technical approach identifies unit operations and allocates one or more unit operations to each work group. The work group then has the responsibility for allocating tasks amongst its members and for training its members so that eventually each individual is competent to carry out all tasks.

The analysis of the social part of the work system consists of analysing the role relationships within the system, in other words who needs to work with whom for the system to function efficiently. In addition an analysis is made of the job satisfaction needs of individuals in the department, using the theoretical framework described earlier. 
An important aspect of the socio-technical approach is the notion of 'control'. A further analysis of the technical part of the system is carried out using the variance analysis technique already described. Operating efficiency is then improved by giving each work group the responsibility for eliminating and correcting variances which occur within the set of unit operations for which it is responsible. Job satisfaction is also improved through handing over this control function to the group. The group requires a set of problem solving skills to enable them to bandle variances successfully and the acquisition of these involves an enhancement of the knowledge of individual group members. It is believed that responsibility for, and ability to solve problems increases the interest of work and provides a sense of achievement.

\section{Einal steps}

Once our new system has been designed it then has to be implemented and its success evaluated. Both of these stages are complex and demanding, and there is no space to discuss them in this paper. We would however suggest that the creation of a small prototype system is a wise safeguard as it enables the selected system design to be tried out and modified before it has wide scale implementation ( 30$)$. When the time for evaluation of the new system arrives we have found that an excellent check of its technical efficiency is the extent to which it has eliminated or gained better control over those variances identified at the diagnostic stage without introducing new ones. A second measure is the extent to which job satisfaction has improved through the creation of a better fit between employee job needs and expectations and the requirements of their jobs on our five satisfaction variables.

\section{CONCLUSION}

The approach set out in this paper stems from the authors' belief that 'participation' should be associated with systems planning and design. This belief is based first on the value position, that people affected by new technical systems should have a right to influence the design of these systems and, second, on the practical proposition that the future users of systems will possess a detailed knowledge of both the efficiency requirements of the situations in which they work and their own job satisfaction needs. They will, at the same time, have a knowledge gap in that they are unlikely to have much experience of the analytical and synthesising skills that are required in systems design. The authors have attempted to fill this gap by. developing a set of simple, structured procedures that will take a newly formed design team from an initial diagnosis which covers efficiency, job satisfaction and future contingency needs, through the setting and weighting of objectives and the development of alternative strategies, to a choice of system and its socio-technical design. Table 1 shows these different procedural steps used at different organisational levels and with different forms of participation. 


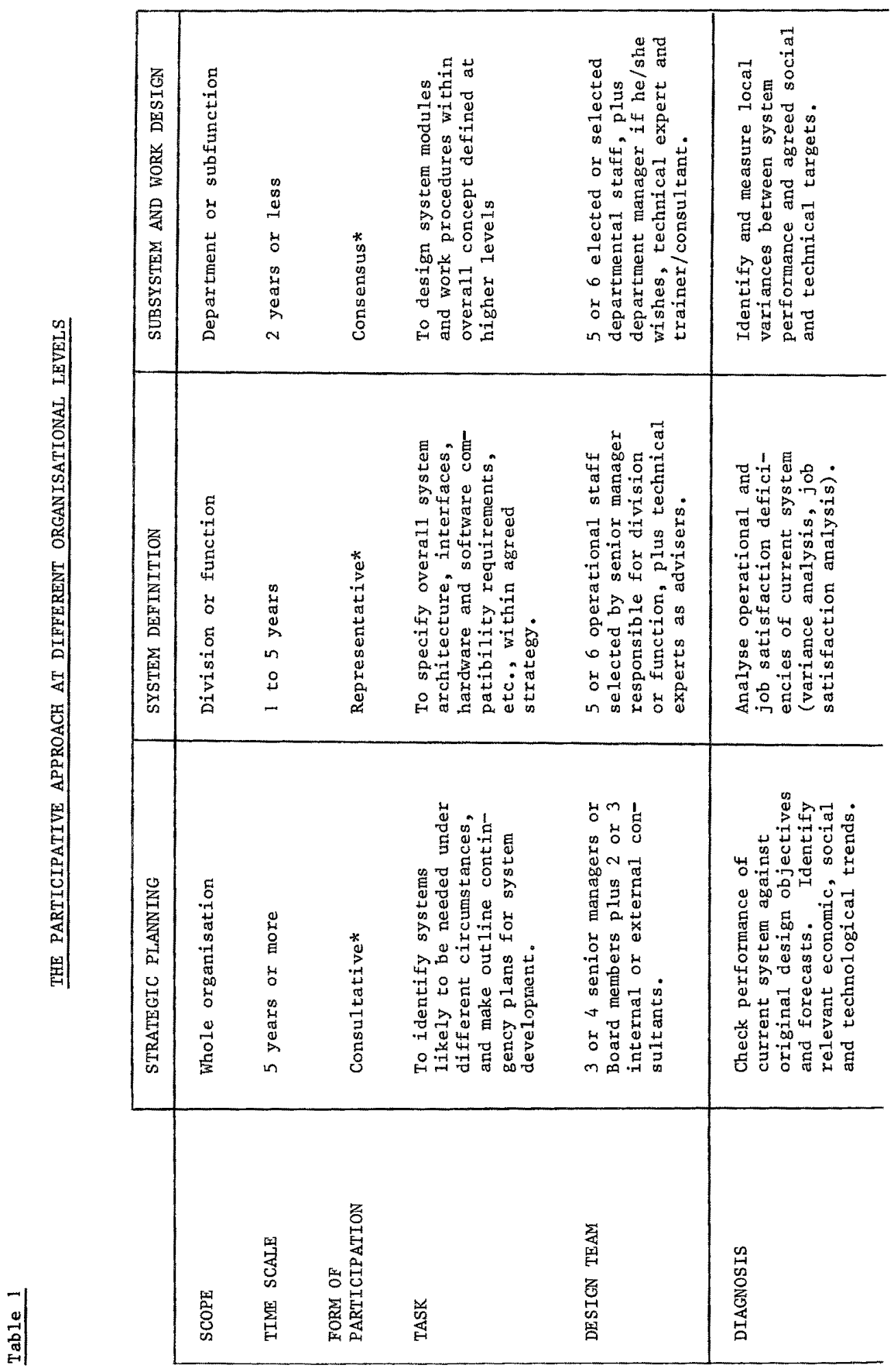



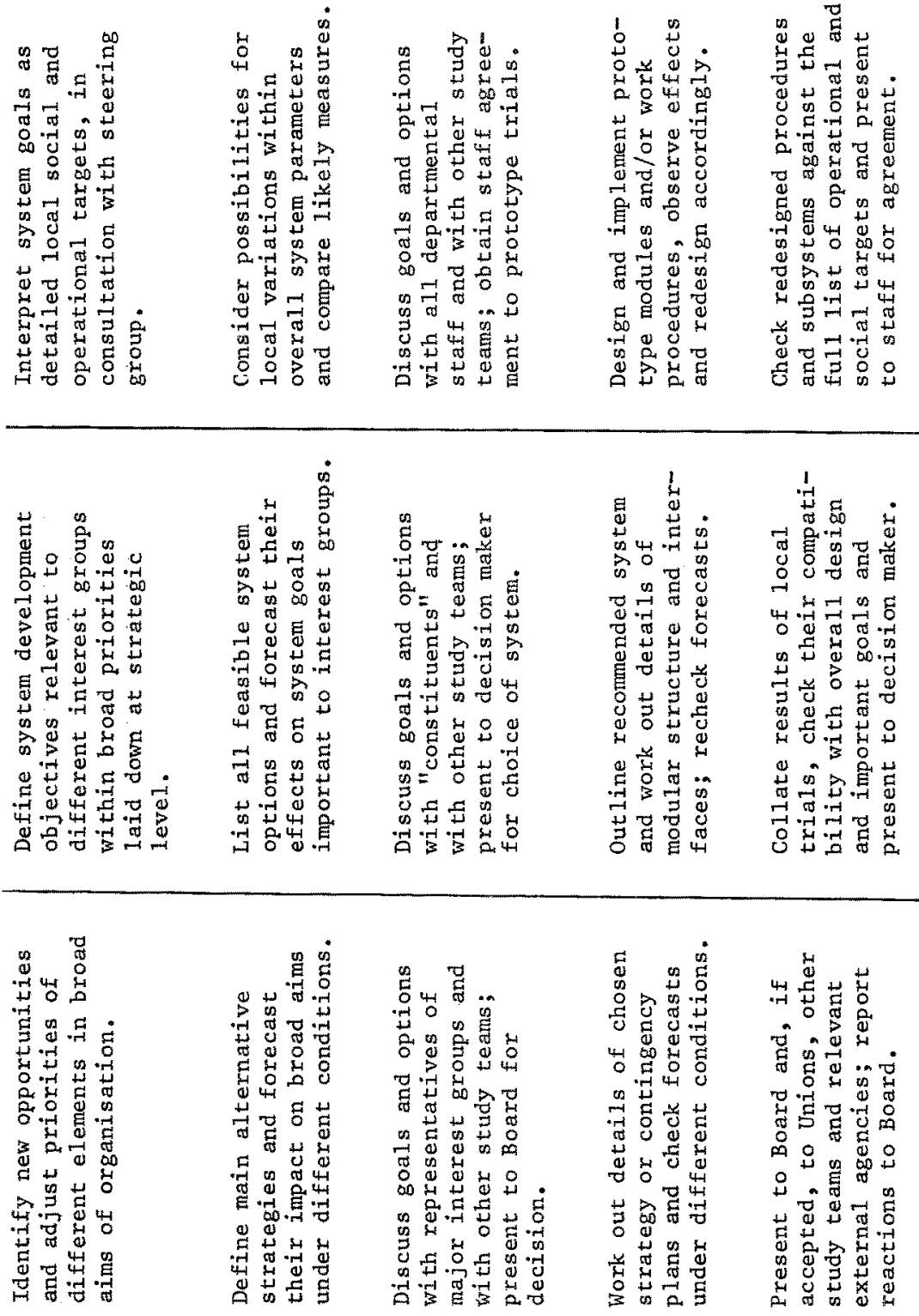

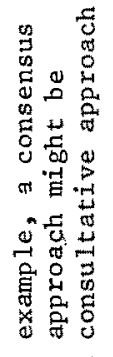

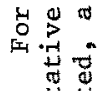

i 菏苋

可 ơ

공

究峦

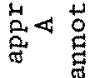

๑.

出出

网

盆点品

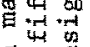

青

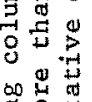

岁

突豆

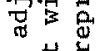

苟

돈

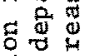

告的家

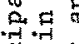

연

垔:

㟧离舟

몽묘

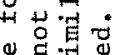

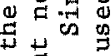

5

ه

\begin{tabular}{|c|c|c|c|c|}
\hline 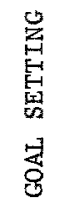 & 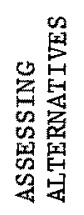 & 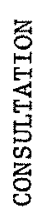 & 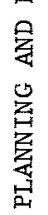 & 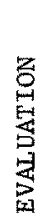 \\
\hline
\end{tabular}




\section{REFERENCES}

1 LAND, F.F. Criteria for the evaluation and design of effective systems, Economics of Informatics, A.B. Frielink ed., North Holland, 1975

2 ZIMA, K.P. Project-Wirtschaftlichkeitsrechnungen bei der ESSO AG, Proceedings of the Informationsforum "Die Wirtschaftlichkeit von Informations- und Kommunikationssysternen", B.TFOA, 1977

3 MARSCHAK, J. Economics of information systems, Journal of the American Statistical Association, March 1971

4 LEVEN, P.H. On decision and decision-making, Systems and Management Annual, 1974, R.L. Ackoff ed., Petrocelli Books, 1974

5 FLOWERDEW, A.D.J. \& WHITEHEAD, C.M.E. Problems of measuring the benefits of scientific and technical information, Economics of Informatics, A.B. Frielink ed., North Holland, 1975

6 ZALANY, M. Introductory notes on conflict dissolution, Proceedings of ORSA/TIMS Joint National Meeting, Philadelphia, 1976

7 DUZMOVIC, J.J. Criteria aggregation technique for evaluation, optimisation and selection of computer systems, University of Belgrade, March 1976

8 ZANGEMEISTER, C. 'Nutzwertanalyse', in The Economics of Informatics, A.B. Frielink, ed., North Holland, 1975

9 GENKINGER, P.F. Implementing 'Nutzwertanalyse', in Economics of Informatics, A.B. Frielink, ed., North Holland, 1975

10 SIBLEY, E*H. Evaluation and selection of data base systems, Database Systems Infotech State of the Art Report, 1975

11 BUSCH, U. \& KROPP, I. Kombination von Monetaren Wirtschaft-Lichkeitścrechnungen und Nutzwertanalysen, Proceedings of the Informationsforum "Die Wirtschaftlichkeit von Informations- und Konmunikationssystemen", BIFOA, 1977

12 LAND, F.F. Evaluation of systems goals in determining a decision strategy for a computer based information system, The Computer Journal, Vol.19, No.4, November 1976

13 HAWGOOD, J. Quinquevalent quantification of computer benefits, Economics of Informatics, A.B. Frielink ed., North Holland 1975

14 MUMFORD, E. Towards the democratic design of work systems, Personnel Management, Vo1.8, No.9, September 1971

15 SUSMAN, G. A socio-technical analysis of participative management, Praeger, 1976

16 OZBEKHAN, H. Towards a general theory of planning, in $\mathrm{E}$. Jantsch (ed.), Perspectives of Planning, $\mathrm{OECD}, 1969$

17 BLAKE, R., SHEPARD, H. \& MOUTIN, J. Managing intergroup conflict in industry, Houston, Gulf Publishing, 1964

18 GUSTAFSON, H.W. 'Force-loss lost analysis', paper presented to the AWV-Fachseminar: Das Human Kapital der Unternehem, Bonn, September 1974. Quoted in A. Hopwood

'Towards assessing the economic costs of new forms of work organisation', Accounting, Organisations and Society, 1977

19 MUMFORD, E. \& PETTIGREW, A. Implementing strategic decisions, Longmans, 1975 
20 DAVIS, L. Job satisfaction research: the post industrial view, Industrial Relations, Vol.10, 1971

21 TAYLOR, J.C. The human side of work: the socio-technical approach to work design, Personnel Review, Vo1.4, No.3, Summer 1975

22 MUNFORD, E. Job satisfaction: a method of analysis, Personnel Review, Vol.1, No.3, Sumner 1972

23 HERZBERG, F. Work and the nature of man, London, Staples Press, 1966

24 COOPER, R. How jobs motivate, Personne1 Review, Vol.2, Spring 1973

25 LAND, F.F. Evaluation of systems goals in determining a design strategy for a computer based information system, Computer Journal, November 1976

26 HAWGOOD, J. Participative assessment of library benefits, Drexe1 Library Quarterly, July 1977

27 HAWGOOD, J. How to apply participative planning to your library policy change, Automation Benefit Appraisal Consultants, Durham, 1977

28 ZADEH, L.A. Outline of a new approach to the analysis of complex systems and decision processes, IEEE Trans. on Systems, Man and Cybernetics, Vo1.SMC-3, No. 1, January 1973

29 ROUSSEAU, D. Technological differences in job characteristics, employee satisfaction, and motivation: a synthesis of job design research and socio-technical systems theory, Organisational Behaviour and Human Performance, 1977, Vo1.19, pp.18-42

30 EARI, M. Prototype systems for management information and control (to be published short1y) 